\title{
A swift, easy and cheap protocol to evaluate the tooth bleaching in vitro
}

\author{
Klayann-Varejão-de Freitas Penha, Anne-Carolyne-Santos Sousa, Camila-Araújo Oliveira, Raissa-Silva-Bacelar \\ de Andrade, Daniel-Fernando-Pereira Vasconcelos
}

Correspondence:

Universidade Federal do Piaui - UFPI

Campus Ministro Reis Veloso

Colegiado de Biomedicina

Av. São Sebastião, 2819, Reis Veloso

Parnaiba - PI-Brazil, 64204-035

vasconcelos@ufpi.edu.br

\begin{abstract}
Penha KVF, Sousa ACS, Oliveira CA, de Andrade RSB, Vasconcelos DFP. A swift, easy and cheap protocol to evaluate the tooth bleaching in vitro. J Clin Exp Dent. 2018;10(6):e579-84.

http://www.medicinaoral.com/odo/volumenes/v10i6/jcedv10i6p579.pdf
\end{abstract}

Received: $14 / 03 / 2018$ Accepted: 11/04/2018

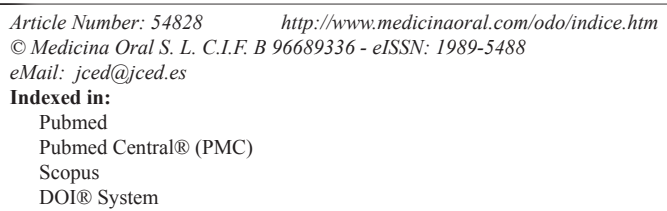

\begin{abstract}
Background: This study aims to develop a protocol that optimizes in vitro dental bleaching procedures in a cheap, fast and accessible manner.

Material and Methods: 18 bovine incisors were cut and polished in enamel/dentin and submitted to staining in coffee solution during 72 hours. After the standardization and staining of the enamel surfaces, three groups ( $\mathrm{n}=6$ ) were formed to receive three different gels, WHITENESS (commercial gel); $\mathrm{H}_{2} \mathrm{O}_{2}-5 \%$ (manipulated gel); CARBOPOL GEL (manipulated gel and without $\mathrm{H}_{2} \mathrm{O}_{2}$ ). The color of the enamel surfaces was evaluated using digital images, obtained with digital camera and controlled luminosity, before and after staining, as well as after each bleaching step.

Results: The average bleaching after 48 hours of procedure was: WHITENESS with $13.6( \pm 1.2)$; $\mathrm{H}_{2} \mathrm{O}_{2}(5 \%)$ with $9.8( \pm 1.4)$ and CARBOPOL GEL with $2.9( \pm 0.6)$. After 72 hours, WHITENESS presented a mean of $15.8( \pm 0.7)$, the $\mathrm{H}_{2} \mathrm{O}_{2}$ group (5\%) $14.4( \pm 1.5)$ and CARBOPOL GEL $4.6( \pm 1.0)$. After completing 96 hours of whitening, WHITENESS presented an average of $18.3( \pm 0.8), \mathrm{H}_{2} \mathrm{O}_{2}(5 \%) 16.7( \pm 1.4)$ and CARBOPOL GEL $7.3( \pm 0.8)$. Our data demonstrated that the protocol development for us can be used to evaluate dental bleaching in a short time, with 96 hours already was possible to detect significant differences, when compared with the longer times of experimental dental bleaching.

Conclusions: The proposed protocol guarantees statistically significant results in 96 hours, confirming the efficacy, cheapness, viability and practicality of the protocol developed in this study.
\end{abstract}

Key words: Enamel, color, aesthetics.

\section{Introduction}

The search for the improvement of dental aesthetics is increasingly present in modern society (1). Satisfaction with dental appearance is strongly influenced by tooth color (2-5). With the increase in aesthetic value and the search for whitening procedures, the research was con- ducted by techniques and procedures that guarantee results without compromising the health of dental tissues (2), which could affect the subject's quality of life (6). Increasingly young people and children are worried and dissatisfied with the aesthetic dentistry. Aesthetic problems in childhood and adolescence can significantly in- 
fluence psychosocial development and interactions with colleagues. In a study in the United States with 2,495 children, 31.6\% were dissatisfied with tooth color and $19 \%$ of parents shared this dissatisfaction (7). A study carried out in Malaysia showed that $56.2 \%$ of 235 patients were not satisfied with the color of the teeth, and $48.1 \%$ wanted to perform dental whitening (8).

Tooth whitening is a process that seeks to make the tooth as clear as possible. The color of the teeth is determined by the combined effects of the intrinsic and extrinsic dyes, intrinsic color and especially those associated with the property of dispersion and adsorption of enamel and dentin light and extrinsic colors that tend to form in areas of the teeth which are less accessible for tooth brushing and are often promoted by smoking, dietary intake, the use of certain agents such as chlorhexidine or metal salts $(9,10)$.

Bleaching is performed according to the active agent, especially hydrogen peroxide $\left(\mathrm{H}_{2} \mathrm{O}_{2}\right)$, or one of its precursors, such as carbamide peroxide (11-13). $\mathrm{H}_{2} \mathrm{O}_{2}$ acts as an important agent in tooth whitening, releasing free radicals and oxidative chromophore molecules through redox processes. The penetration of oxidative agents into dental structures breaks these chromophore molecules into less complex molecules, generating a clearer dental appearance (14). The chemical reaction of the reagent in contact with an organic matter, including pigments and chromophores, is the chemical basis for tooth whitening (15).

Many are the protocols available for teeth whitening. However, in most of them, the high cost of the equipment, the complexity of the process and the long period to achieve desirable results are disadvantageous factors, requiring alternatives that obtain similar, more practical and cheaper results (16).

Most of the available in vitro dental whitening protocols perform the dental whitening procedure at times greater than 96 hours, making them more time consuming $(17,18)$. This study aims to develop a protocol that performs dental bleaching procedures in vitro in a cheap, fast and accessible manner.

\section{Material and Methods}

-Specimen preparation

Eighteen bovine incisor teeth that were extracted and randomly selected after being collected and disinfected with chlorhexidine $2 \%$. The teeth were obtained from a local slaughterhouse. Therefore, the approval of the Ethics Committee was not necessary for the present article, since the teeth were destined to the discard.

With the help of a clamp (Professional Line Number Lathe 3 / METALSUL - TBP05), the teeth were established by the root area, for better manipulation and safety in the accomplishment of dental crown cuts, the crowns were cut in enamel/ dentin measurements of $5 \mathrm{~mm}$ of width by $10 \mathrm{~mm}$ of length with a cutting disc $(22 \mathrm{~mm} \times 0.6 \mathrm{~mm}$ / 223 - Detoriom) as shows in Fig. 1 A,B.

The enamel/ dentin specimens were randomly attached with glue (Super Bonder $\AA$, Itapevi, SP, Brazil) on glass slides through the dentin, exposing the dental enamel, with 3 specimens on each slide (Fig. 1B). Then, the surfaces of the enamel were polished using a micro electric motor (LB 100 Beltec) with a thick granular abrasion stone (DhPro) (Fig. 1C), followed by fine granular abrasion stone (DhPro) (Fig. 1D), removing 200 $\mu \mathrm{m}$ from the enamel surface to obtain smooth surfaces, completing the polishing with a rubber cup (Fig. 1E).

-Staining of specimen

The specimens were stained by full immersion of the finished slides in a coffee solution, which was renewed every 24 hours for 3 days (Fig. 2A). At each refill of coffee solution, prepared by mixing $500 \mathrm{ml}$ of boiled water with $45 \mathrm{~g}$ of soluble coffee (Nescafe $\left.{ }^{\circledR}\right)$, colorful images were taken of specimens. After the period of staining, the specimens were washed in running water per 30 seconds (Fig. 2B), removing excess coffee from the surfaces. Subsequently, the samples were left at room temperature for a few minutes for complete drying. After drying, the final color images of the specimens were obtained.

-Data collection

The specimen's digital pictures were carefully taken with a digital camera (Samsung CMOS, 3.264x1.836 pixels resolution, $3.70 \mathrm{~mm}$ focal length and 2.6 aperture. Samsung, South Korea). A white background was used and the ambient light was controlled to avoid shading, being the pictures taken at the same time of the day.

The first colorimetrical analysis was made by a scientific pictures processing software (ImageJ, 32-bit, Microsoft Java) which evaluates coloration through pixels count. On each specimen was selected a 20 to 21 pixels area for gray/ brightness level analysis of the image pixels represented by the red-R (Fig. 2C), green-G (Fig. 2D) and blue-B (Fig. 2E) colors bands intensity, on the RGB system.

The data obtained were saved on a worksheet and subsequently transformed to CIELAB colors space (hthttp:// colormine.org/convert/rgb-to-lab) in which the points provide more uniform numeric differences regarding visual differences (10) (Fig. 2F).

-Colorimetric measurement

As a first method of colorimetric measurement, ImageJ software, which is free and consolidated for image processing and analysis, was developed by Wayne Rasband at the National Institute of Mental Health, USA (19).

For the samples shade colors analysis, each picture was separately open and analyzed on 3 images of distinct gray shades relating to the colors: red, green and blue respectively, and then the color average was assessed for each shade, being the result variable from 0 to 255 on the RGB scale. 

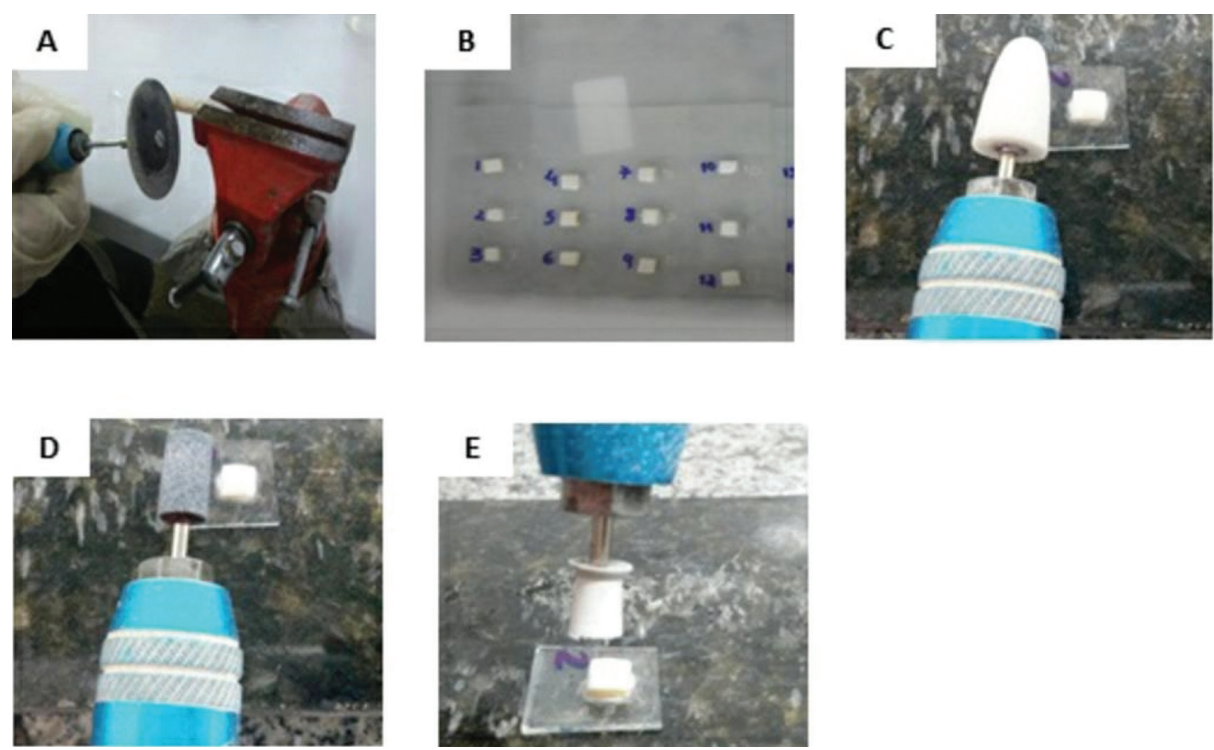

Fig. 1: (A) The clamp (Professional Line Number Lathe 3 / METALSUL - TBP05), the teeth were established by the root area, for better manipulation and safety in the accomplishment of dental crown cuts, the crowns were cut in enamel/ dentin measurements of $5 \mathrm{~mm}$ of width by $10 \mathrm{~mm}$ of length with a cutting disc (22mm x 0.6mm / 223 - Detoriom). (B) The enamel/ dentin specimens were randomly attached with glue (Super Bonder ${ }^{\circledR}$, Itapevi, SP, Brazil) on glass slides through the dentin, exposing the dental enamel, with 3 specimens on each slide. (C) the surfaces of the enamel were polished using a micro electric motor (LB 100 Beltec) with a thick granular abrasion stone (DhPro). (D) followed by fine granular abrasion stone (DhPro). (E) removing $200 \mu \mathrm{m}$ from the enamel surface to obtain smooth surfaces, completing the polishing with a rubber cup.
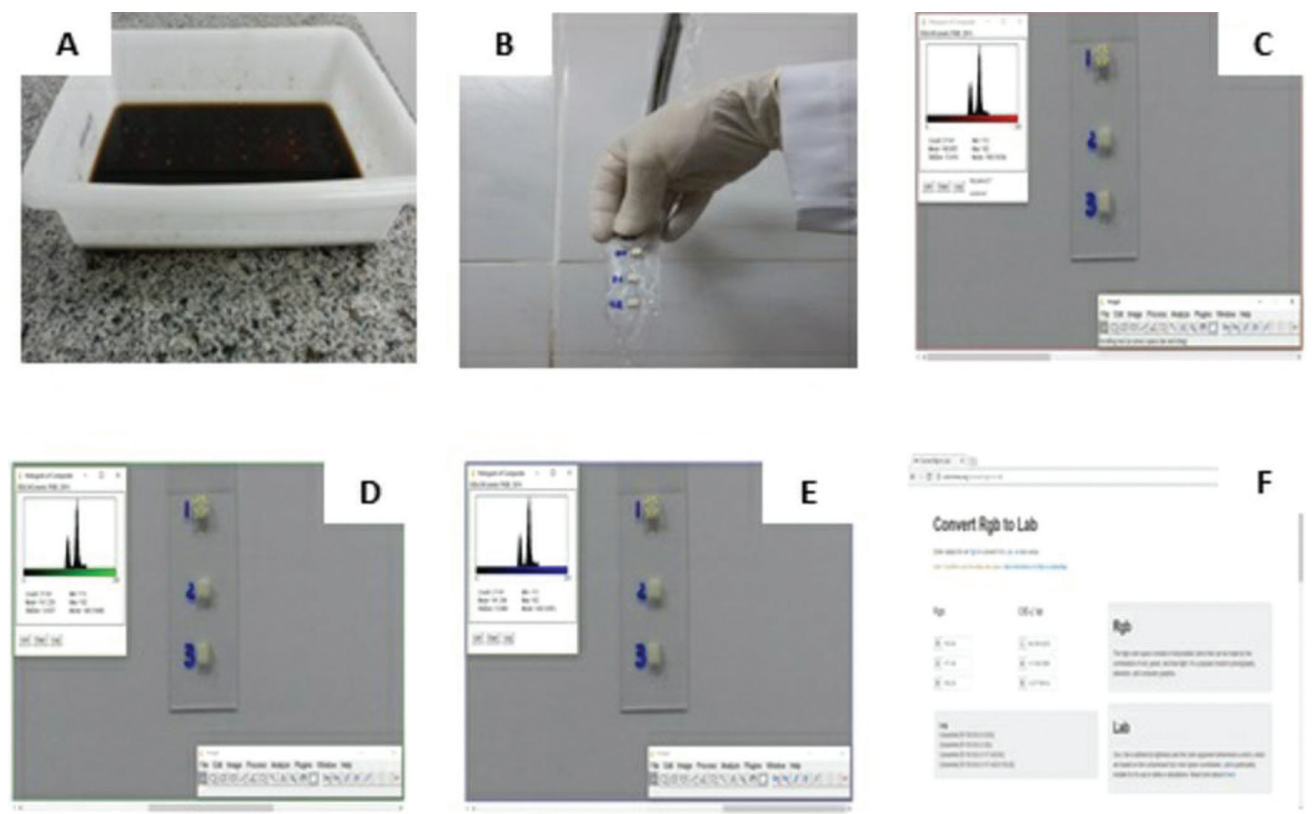

Fig. 2: (A) The specimens were stained by full immersion of the finished slides in a coffee solution, which was renewed every 24 hours for 3 days. (B) After the period of staining, the specimens were washed in running water per 30 seconds, removing excess coffee from the surfaces. The colorimetrical analysis was made by a scientific pictures processing software (ImageJ, 32-bit, Microsoft Java) which evaluates coloration through pixels count. (C) The specimen was selected a 20 to 21 pixels area for gray/ brightness level analysis of the image pixels represented by the red-R.. (D) The specimen was selected a 20 to 21 pixels area for gray/ brightness level analysis of the image pixels represented by the green-G. (E) The specimen was selected a 20 to 21 pixels area for gray/ brightness level analysis of the image pixels represented by the blue-B. colors bands intensity, on the RGB system. (F) The data obtained were saved on a worksheet and subsequently transformed to CIELAB colors space (hthttp://colormine.org/ convert/rgb-to-lab) in which the points provide more uniform numeric differences regarding visual differences. 
In order to standardize color measurement, it was used Colormine (C) online software to the conversion of the RGB scale to a CIE L* ab color scale, which is the present most used for color quantitative description of an object due to its uniformity, using the following equation: CIE $\mathrm{L}^{*}=100 * \mathrm{~L} / 255$. This system is based on three elements: luminosity, tone and saturation or chromaticity. Color parameters indicate luminosity ( $\left.\mathrm{L}^{*}\right)$ which varies from 0 (absolute black) to 100 (absolute white), the coordinate $\mathrm{a}^{*}$ positions on the green axis (if negative $a-$ ) - red (if positive $a+$ ), the coordinate $b^{*}$ positions on the yellow axis (in negative b-) - blue (if positive $\mathrm{b}+$ ).

-Different gel treatments

After the tooth staining period, the specimen slides were randomly divided into three groups $(\mathrm{N}=6)$ : WHITENESS Group (16\%) (Whiteness Perfect, Joinvile, SC, Brazil), $\mathrm{H}_{2} \mathrm{O}_{2}$ Group (5\%) (Farmafórmula, Parnaíba, PI, Brazil) and CARBOPOL GEL Group (Farmafórmula, Parnaíba, PI, Brazil) to receive bleaching procedures.

Carbamide peroxide, whitening agent present in the WHITENESS gel, is the agent most used in home bleaching, also being used in the office varying only the concentration of the active. Carbamide peroxide has many advantages, such as not requiring heat and being effective and safe with minimal side effects. $\mathrm{H}_{2} \mathrm{O}_{2}$ is the most used agent in office, being activated with light or heat; its results are accelerated, being more caustic, what requires a greater care in the application, since it can produce side effects greater than the effects produced by carbamide peroxide. Carbopol is an acrylic polymer with thickening function, increasing the adhesion in the dental tissues, releasing oxygen more slowly (20).

Each bleaching gel was handled and managed according to the manufacturer's instructions. A $2 \mathrm{~mm}$ thick layer was applied throughout the experimental area of the enamel surface of each specimen in each group.
Every 24 hours, the specimens were washed with distilled water and toothbrush for a complete removal of the gel. Subsequently, they were left at room temperature for 30 minutes for drying. Images of the specimens were obtained at each reapplication interval of the gels. The bleaching period of the groups occurred for 5 days in a hermetically sealed container with relative humidity control in $85 \%$.

-Statistical analysis

The data are expressed as mean \pm SEM and/or median. The normality of the data was tested through the Shapiro-Wilk Test. Difference between the two groups was analyzed using Mann-Whitney U test, for no-parametric data, and test $\mathrm{T}$ unpaired, for parametric data.

\section{Results}

After $48 \mathrm{~h}$ the mean bleaching rate of the samples submitted to the WHITENESS gel was $13.6( \pm 1.2)$, whereas the samples submitted to $\mathrm{H}_{2} \mathrm{O}_{2}$ presented a mean of $9.8( \pm 1.4)$ and the samples in which only CARBOPOL GEL had a mean bleaching of $2.9( \pm 0.6)$. After 72 hours (Fig. 1B), WHITENESS had a mean of $15.8( \pm 0.7)$, the gel with $\mathrm{H}_{2} \mathrm{O}_{2}$ presented an average of $14.4( \pm 1.5)$, and CARBOPOL GEL 4.6 ( \pm 1.0). After completing 96h whitening, WHITENESS presented a lightening average of $18.3( \pm 0.8), \mathrm{H}_{2} \mathrm{O}_{2}$ cleared an average of $16.7( \pm 1.4)$ and CARBOPOL GEL $7.3( \pm 0.8)$. It can be seen that there was no statistically significant difference between WHITENESS and $\mathrm{H}_{2} \mathrm{O}_{2}$ groups, while CARBOPOL GEL group obtained a significant lower whitening action than both previous groups (Table 1). Thus, the gel that most provided whitening was WHITENESS.

In all the whitening (Fig. 3A), when comparing the results obtained in $48 \mathrm{~h}$ and $72 \mathrm{~h}$, there are no significant difference between the groups (represented by letter "a"), the same happens when compared the results of $72 \mathrm{~h}$ and $96 \mathrm{~h}$ (represented by letter "b"). However, the com-

Table 1: Average bleaching rate over 48 hours, 72 hours and 96 hours.

\begin{tabular}{|c|c|c|c|}
\hline Groups & 48 Hours & 72 Hours & 96 Hours \\
\hline $\begin{array}{c}\text { WHITENESS 16\% } \\
\text { (comercial gel) }\end{array}$ & $13.6 \pm 1.2$ & $15.8 \pm 0.7$ & $18.3 \pm 0.8$ \\
\hline $\begin{array}{c}\mathrm{H}_{2} \mathrm{O}_{2} 5 \% \\
\text { (manipulated gel) }\end{array}$ & $9.8 \pm 1.4$ & $14.4 \pm 1.5$ & $16.7 \pm 1.4$ \\
\hline $\begin{array}{l}\text { CARBOPOL GEL } \\
\text { (without } \mathrm{H}_{2} \mathrm{O}_{2} \text { ) }\end{array}$ & $2.9 \pm 0.6^{*}$ & $4.6 \pm 1.0^{*}$ & $7.3 \pm 0.8^{*}$ \\
\hline
\end{tabular}




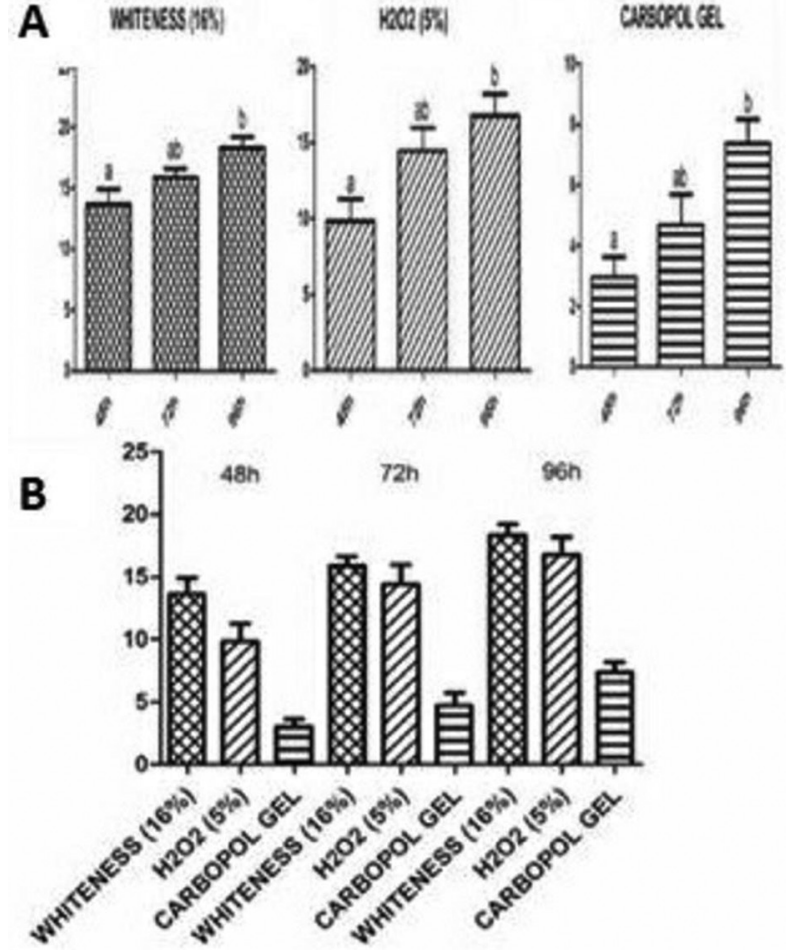

Fig. 3: (A) Results obtained by each group in relation to time: WHITENESS, H2O2, CARBOPOL GEL. (B) Results obtained by all groups in $48 \mathrm{~h}, 72 \mathrm{~h}$ and $96 \mathrm{~h} . *$ Same letters represent that there was no statistically significant difference between the groups, while different letters represent that there was statistically significant difference.

parison between whitening produced in $48 \mathrm{~h}$ and $96 \mathrm{~h}, p$ $<0.05$ (represented by different letters), characterizing a statistically significant difference occurrence.

The whitening provided by the bleaching gels was gradual (Fig. 3B). The difference in whitening provided by WHITENESS and $\mathrm{H}_{2} \mathrm{O}_{2}$ was not statistically significant in all evaluated periods. When compared with $\mathrm{H}_{2} \mathrm{O}_{2}$ and WHITENESS both with CARBOPOL GEL, there were differences with $p<0.05$.

\section{Discussion}

The in vitro dental bleaching protocol developed in this study offers a quick, inexpensive and simple methodology that allows an evaluation of tooth enamel whitening products in 96 hours.

In addition to oral health, dental aesthetics has become a priority in dental treatments. Color changes are the most common aesthetic imbalance of smile, because white teeth are considered a sign of care and beauty, which show surprising effects on self-esteem. The demand for teeth whitening has grown almost exponentially in recent years in the United States, of the 1,181 eligible surveys for analysis performed with a weighted sample of members of the American Association of Orthodontists, $88.8 \%$ of orthodontists across the country had patients who requested Bleaching (21). With the increase of aesthetic valorization and the search for whitening procedures, it is necessary to study new methodologies, which guarantee speed, practicality and accessibility, without compromising the healthy dental structure.

Previous studies (22) showed that there are similarities between human and bovine teeth, being these objects of choice for this protocol, since they are easy to obtain, without the need for approval by the Ethics Committee, which provides agility in the accomplishment of the experiment. In addition, a bovine mandible presents eight incisors of larger dimensions than the human ones, favoring the research with tests in a single element, as well as its handling and preparation. When compared to other methodologies (23-25), this protocol guarantees, in simple steps of polishing and staining, satisfactory results for evaluating dental bleaching procedures.

The color of the tooth is determined by a combination of different optical properties of enamel, dentin and pulp, staining varies according to etiology, appearance and adhesion to dental structure (26). The coloration of the dental surface by colored solutions, coffee and tea (27), beverages such as red wine (28) and blood (10), has been reported in many studies. These substances can lead to yellow and brown spots on the teeth (29). In this study, we opted for the use of coffee, because it is inexpensive, easy to prepare, and routinely used by most people. Color determination can be performed with spectrophotometers, however the technique is time-consuming and costly, since it requires a specific device (16). However, the analysis of tooth staining chosen for this protocol through digital photographs is relatively simple and sufficiently accurate to allow evaluation of the therapeutic outcome of teeth whitening procedures, although some factors affect color and brightness even performing a highly standardized methodology (30).

Using the adapted methodology (9), the photographs obtained were analyzed in Image J software due to its easy of manipulation and accessibility, unlike Adobe Photoshop, which is a private domain software that has tools that require user dexterity. ImageJ is an image editor compiled in Java, which allows it to run on any operating system with platform support, besides being free, its tools are practical, which gives it a large community of users in scientific research.

When analyzing the obtained results, it is observed that the groups evaluated had a gradual increase in bleaching and that the proposed protocol guarantees statistically significant results in 96 hours. Therefore, the effectiveness of the procedure performed is emphasized, considering the practicality of its handling and access, which gives it a reputation in the scientific field.

\section{Conclusions}

The proposed protocol guarantees statistically signifi- 
cant results in 96 hours, confirming the efficacy, cheapness, viability and practicality of the protocol developed in this study.

\section{References}

1. Venete A, Trillo-Lumbreras E, Prado-Gascó VJ, Bellot-Arcís C, Almerich-Silla JM, Montiel-Company JM. Relationship between the psychosocial impact of dental aesthetics and perfeccionism and selfsteem. J Clin Exp Dent. 2017;9:e1453-e1458.

2. Van der Geld P, Oosterveld P, Van Heck G, Kuijpers-Jagtman AM. Smile attractiveness: self-perception and influence on personality. Angle Orthod. 2007;77:759-65.

3. Samorodnitzky-Naveh GR, Geiger SB, Levin L. Patients' satisfaction with dental esthetics. J Am Dent Assoc. 2007;138:805-8.

4. Silvola AS, Varimo M, Tolvanen M, Rusanen J, Lahti S, Pirttiniemi P. Dental esthetics and quality of life in adults with severe malocclusion before and after treatment. Angle Orthod. 2014;84:594-9.

5. Kershaw S, Newton JT, Williams DM. The influence of tooth colour on the perceptions of personal characteristics among female dental patients: comparisons of unmodified, decayed and "whitened" teeth. Br Dent J. 2008;204:256-7.

6. Meireles SS, Goettems ML, Dantas RV, Bona ÁD, Santos IS, Demarco FF. Changes in oral health related quality of life after dental bleaching in a double-blind randomized clinical trial. J Dent. 2014;42:114-21.

7. Shulman JD, Maupome G, Clark DC, Levy SM. Perceptions of desirable tooth color among parents, dentists and children. J Am Dent Assoc. 2004;135:595-604.

8. Tin-Oo MM, Saddki N, Hassan N. Factors influencing patient satisfaction with dental appearance and treatments they desire to improve aesthetics. BMC Oral Health. 2011;11:6.

9. Peskersoy C, Tetik A, Ozturk VO, Gokay N. Spectrophotometric and computerized evaluation of tooth bleaching employing 10 different home-bleaching procedures: In-vitro study. Eur J Dent. 2014;8:538-45.

10. Joiner A. Tooth colour: a review of the literature. J Dent. 2004;32:3

12.

11. Tredwin CJ, Naik S, Lewis NJ, Scully C. Hydrogen peroxide tooth-whitening (bleaching) products: review of adverse effects and safety issues. Br Dent J. 2006;200:371-6.

12. Spalding M, Taveira LA, de Assis GF. Scanning electron microscopy study of dental enamel surface exposed to $35 \%$ hydrogen peroxide: alone, with saliva, and with $10 \%$ carbamide peroxide. J Esthet Restor Dent. 2003;15:154-65.

13. Marson FC, Sensi LG, Vieira LC, Araújo E. Clinical evaluation of in-office dental bleaching treatments with and without the use of light-activation sources. Oper Dent. 2008:33:15-22.

14. Borges AB, Zanatta RF, Barros AC, Silva LC, Pucci CR, Torres CR. Effect of hydrogen peroxide concentration on enamel color and microhardness. Oper Dent. 2015;40:96-101.

15. Goldberg M, Grootveld M, Lynch E. Undesirable and adverse effects of tooth-whitening products: a review. Clin Oral Investig. 2010;14:1-10.

16. Lath DL, Smith RN, Guan YH, Karmo M, Brook AH. Measurement of stain on extracted teeth using spectrophotometry and digital image analysis. Int J Dent Hyg. 2007;5:174-179.

17. Henn-Donassollo S, Fabris C, Gagiolla M, Kerber Í, Caetano V, Carboni V, et al. In situ and in vitro effects of two bleaching treatments on human enamel hardness. Braz Dent J. 2016;27:56-9.

18. Mondelli RF, Azevedo JF, Francisconi AC, Almeida CM, Ishikiriama SK. Comparative clinical study of the effectiveness of different dental bleaching methods - two year follow-up. J Appl Oral Sci. 2012;20:435-43.

19. Brunk M, Sputh S, Doose S, van de Linde S, Terpitz U. HyphaTracker: An ImageJ toolbox for time-resolved analysis of spore germination in filamentous fungi. Sci Rep. 2018;8:605.

20. Wang C, Lucas R, Smith AJ, Cooper PR. An in vitro screening assay for dental stain cleaning. BMC Oral Health. 2017;17:37.

21. Slack ME, Swift EJ Jr, Rossouw PE, Phillips C. Tooth whitening in the orthodontic practice: A survey of orthodontists. Am J Orthod Dentofacial Orthop. 2013;143:S64-71

22. Yassen GH, Platt JA, Hara AT. The use of bovine teeth as a substitute for human teeth in dentistry research: a review of the literature. $\mathrm{J}$ Oral Sci. 2011;53:273-82.

23. Sulieman M, Addy M, Rees JS. Development and evaluation of a method in vitro to study the effectiveness of tooth bleaching. J Dent. 2003;31:415-22.

24. Caneppele TM, Rocha Gomes Torres C, Huhtala MF, Bresciani E. Influence of whitening gel application protocol on dental color change. ScientificWorldJournal. 2015;2015:420723.

25. Cal E, Güneri P, Kose T. Comparison of digital and spectrophotometric measurements of colour shade guides. J Oral Rehabil. 2006;33:221-8.

26. Sulieman M, Addy M, MacDonald E, Rees JS. The effect of hydrogen peroxide concentration on the outcome of tooth whitening: an in vitro study. J Dent. 2004;32:295-9.

27. Gross MD, Moser JB. A colorimetric study of coffee and tea staining of four composite resins. J Oral Rehabil. 1977;4:311-22.

28. Berger SB, Coelho AS, Oliveira VA, Cavalli V, Giannini M. Enamel susceptibility to red wine staining after $35 \%$ hydrogen peroxide bleaching. J Appl Oral Sci. 2008;16:201-4.

29. Topcu FT, Sahinkesen G, Yamanel K, Erdemir U, Oktay EA, Ersahan S. Influence of different drinks on the colour stability of dental resin composites. Eur J Dent. 2009;3:50-6.

30. Llena C, Esteve I, Forner L. Effect of hydrogen and carbamide peroxide in bleaching, enamel morphology, and mineral composition: in vitro study. J Contemp Dent Pract. 2017;18:576-582.

Acknowledgments

Research supported by the CNPq (455104/2014-0).

\section{Authors' contributions}

DFPV contributed in the conception, design, statistical analysis and drafting of the manuscript. RSBA and LFCF contributed in writing the manuscript and its correction. KVFP, ACSS and CAO contributed in the data collection and manuscript drafting. All authors approved the final version for submission

\section{Conflict of interest}

The authors have declared that no conflict of interest exist. 